\title{
EXTRADIÇÃO E CIDADANIA TRANSNACIONAL
}

\author{
EXTRADITION AND TRANSNATIONAL CITIZENSHIP
}

\begin{abstract}
Ana Carolina Souza Fernandes
Mestre em Direito com Ênfase em Relações Econômicas Internacionais pela Pontifícia Universidade Católica de São Paulo (PUC/SP). Pós-graduada em Direito dos Contratos e Direito Societário (L.LM) pelo Insper - Instituição de Ensino e Pesquisa. Pós-graduada em Direito Civil pela Faculdade Autônoma de Direito (FADISP). Bacharel em Direito pela FADISP. Advogada.
\end{abstract}

Samyra Haydêe dal Farra Naspolini Sanches

Doutora em Direito pela PUC/SP. Mestre em Direito pela Universidade Federal de Santa Catarina (UFSC). Bacharel em Direito pela UFSC. Professora do Programa de Mestrado em Direito na Sociedade da Informação das Faculdades Metropolitanas Unidas (FMU). Professora da Faculdade de Direito de Sorocaba (FADI). Experiência na área de gestão e docência em cursos de graduação e pós-graduação (mestrado e especialização) na área de Teoria Geral do Direito, Metodologia da Pesquisa Jurídica e Direitos Humanos. Membro associado e Diretora Executiva do Conselho de Pesquisa e Pós-Graduação em Direito (CONPEDI) e da Associação Brasileira de Ensino do Direito (ABEDi).

Recebido em: 26/08/2018

Aprovado em: 10/01/2019

RESUMO: O conceito de cidadania esteve sempre relacionado ao conceito de nacionalidade, repousando nos critérios territoriais e sanguíneos ou até misto para fins de atribuição desta última. Observe-se que, no Brasil as condições para atribuição da nacionalidade estão previstas no artigo 12 da Constituição Federal de 1988 (“CF/88”). Tal inter-relação é fruto da chamada Teoria Geral do Estado, na qual a soberania absoluta era considerada um dogma e com base nesse entendimento o Estado-Nação utilizava-se de seu poder para impor aos indivíduos circunscritos naquele território as normas que ele considerasse mais convenientes. Esse cenário foi alterado com o reconhecimento da Organização das Nações Unidas como sujeito de Direito Internacional Público derivado e do surgimento do Direito Internacional dos Direitos Humanos, na segunda metade do Século XX, na qual a noção de cidadania passou a ser interpretada pela Teoria da Democracia e na perspectiva do Estado Constitucional Cooperativo. Nesse sentido, o indivíduo deixa de ser parte da dimensão pessoal exclusiva do Estado para ser recepcionado pelo Direito Internacional dos Direitos Humanos. A despeito desses fatos, a globalização também foi responsável por uma mudança de paradigma no que diz respeito à cidadania, devido ao aparecimento de uma sociedade multicultural. Surge a chamada cidadania transnacional. Assim, o presente artigo busca analisar o seu conceito e eventual incidência sobre o instituto da extradição, por meio de estudos doutrinários e utilizandose do método dedutivo.

Palavras-chave: Extradição. Cidadania Transnacional. Globalização. Integração. Direitos Humanos. 
ABSTRACT: The concept of citizenship has always been related to the concept of nationality, resting on the territorial and blood criteria or even a mix of them for the purpose of assigning the latter. It should be noted that in Brazil the conditions for the attribution of nationality are provided for in article 12 of the Brazilian Federal Constitution of 1988. This interrelationship is the result of the so-called General Theory of State, in which absolute sovereignty was considered a dogma and on the basis of this understanding States used its power to impose on the circumscribed individuals in that territory the rules which they considered most convenient. This scenario was altered with the recognition of the United Nations as a subject if International Public Law and the emergence of the International Human Rights Law, in the second half of the $20^{\text {th }}$ century, in which the notion of citizenship came to be interpreted by the Theory of Democracy and from the perspective of the Cooperative Constitutional State. In this sense, the individual ceases to be part of the exclusive personal dimension of the State to be welcomed by the International Human Rights Law. In spite of these facts, globalization was also responsible for a paradigm shift with regard to citizenship, due to the emergence of a multicultural society. The so-called transnational citizenship emerges. Thus, this article seeks to analyze its concept and possible incidence of the extradition institute, through doctrinal studies and using the deductive method.

Keywords: Extradition. Transnational Citizenship. Globalization. Integration. Human Rights.

SUMÁRIO: Introdução. 1. A Formação da Cidadania no Estado-Nação. 2. A Cidadania na Perspectiva da Teoria da Democracia e do Estado Constitucional Cooperativo. 3. A Transnacionalidade da Cidadania e o Instituto da Extradição. Conclusão. Referências.

\section{INTRODUÇÃO}

A clássica noção de cidadania esteve interligada por muito tempo ao conceito de nacionalidade que, por sua vez, repousava em critérios territoriais e/ou sanguíneos e/ou até mesmo misto. Com efeito, a própria Constituição Federal de 1988 prevê certos critérios para atribuição da nacionalidade em seu artigo 12. Essa interligação entre esses dois institutos faz todo sentido dentro da perspectiva da Teoria Geral do Estado, na qual o Estado-Nação, dotado de soberania absoluta, procura individualizar cada grupo em uma determinada cultura, língua, costume, raça, etc. Nesta perspectiva, o Estado-Nação utiliza-se de seu poder soberano para impor regras que lhe são mais convenientes, qualquer que seja a intenção (por exemplo, segurança nacional na época do regime militar).

Todavia, e principalmente no pós-Segunda Guerra Mundial e com o reconhecimento da Organização das Nações Unidas ("ONU”) e das demais organizações internacionais, inclusive regionais, como sujeitos de Direito Internacional Público, que alterou a dinâmica internacional no que diz respeito à proteção e à preservação dos direitos dos indivíduos, porquanto fez emergir o Direito Internacional dos Direitos Humanos, a ideia de cidadania foi tomando outros contornos, porquanto a relação entre o Estado e o indivíduo começou a ser pautada a partir da Teoria da Democracia e de um novo Estado, qual seja, o Estado Constitucional Cooperativo.

O indivíduo, assim, deixa de ser parte da dimensão pessoal exclusiva do Estado, na qual somente ele lhe conferia direitos, inclusive de nacionalidade (e consequentemente da cidadania, que nada mais é que o "direito a ter direitos"), e passa a ser recepcionado pelo Direito Internacional, nos seus âmbitos regional e universal. Ato contínuo, a globalização tem um efeito imediato na cidadania. A sociedade atual é multicultural e interligada e os ordenamentos jurídicos têm de levar 
em consideração este novo contexto, sob pena de serem negados aos indivíduos seus direitos mais elementares.

Assim, por meio de estudos doutrinários e utilizando-se do método dedutivo, buscar-se-á refletir sobre o conceito de cidadania transnacional frente à possibilidade de extradição, utilizandose como paradigma a recente decisão no Mandado de Segurança n. 33.864 que extraditou uma brasileira nata, sob a justificativa de que, ao "escolher" uma nova nacionalidade (in casu, a norteamericana), abdicou de sua própria, bem como eventuais consequências de uma percepção dessa importância por nossos Tribunais Superiores.

Para tanto, o presente artigo tratará, em um primeiro momento, do conceito da cidadania no Estado-Nação, fundado no Estado de Direito e na clássica Teoria Geral do Estado para, posteriormente, analisar o mesmo contexto sob o prisma da Teoria da Democracia e do Estado Constitucional Cooperativo. Por fim, este artigo abordará a transnacionalidade da cidadania em face do instituto da extradição.

\section{A FORMAÇÃO DA CIDADANIA NO ESTADO-NAÇÃO}

Conforme adverte Dallari (2003, p. 115), não há a possibilidade de se encontrar um único conceito de Estado, uma vez que há enorme variedade de correntes teóricas que podem ser utilizadas, levando-se em conta desde o seu surgimento até todo o seu histórico de configuração. Segundo ao autor:

Encontrar um conceito de Estado que satisfaça a todas as correntes doutrinárias é absolutamente impossível, pois sendo o Estado um ente complexo, que pode ser abordado sob diversos pontos de vista e, além disso, sendo extremamente variável quanto à forma por sua própria natureza, haverá tantos pontos de partida quantos forem os ângulos de preferência dos observadores. [...]. Assim, pois, por mais que os autores se esforcem para chegar a um conceito objetivo, haverá sempre um quantum de subjetividade, vale dizer, haverá sempre a possibilidade de uma grande variedade de conceitos.

O Estado Moderno, considerado aquele Estado unitário dotado de um poder próprio independentemente de quaisquer outros poderes, começou a edificar-se, segundo Skinner (1996, p. 9), entre os fins do século XIII até o final do século XVI e teve o seu ápice no século XVIII, alastrando-se por vários países europeus como a França, a Inglaterra, a Espanha e a Itália. Segundo Wolkmer (1990, p. 24-25), seu aparecimento foi possível

graças à especificidade e à combinação de fatores internos e externos das formações sociais ocidentais, bem como ao impacto de profundas transformações estruturais, de natureza sócio-econômica, político-jurídica e ético-cultural que se articularam nas dimensões daquela temporalidade.

O Estado Moderno apresenta dois momentos distintos. Quando surge, possui a forma do Estado absolutista, legitimado pelo poder monárquico; logo após evolui para o Estado liberal (WOLKMER, 1990, p. 25).

Em sua versão absolutista, o Estado nasce da dissolução da sociedade medieval, que era uma sociedade pluralista, regulada por diferentes fontes de produção jurídica e organizada em vários ordenamentos jurídicos, com a finalidade de fornecer um padrão objetivo de resolução de conflitos. Assim, de acordo com Bobbio (1997, p. 13), "sob o ponto de vista do Direito, a 
monarquia absoluta é a forma de Estado em que não se reconhece mais outro ordenamento jurídico que não seja o estatal, e outra fonte jurídica do ordenamento estatal que não seja a lei”.

Wolkmer (1990, p. 25) elenca as particularidades do Estado absolutista: a) centralização do poder nas mãos do soberano; b) o Estado é territorial e nacional; c) o Estado se reveste de um poder supremo e ilimitado: a soberania; d) o Estado é secular, separado do poder da Igreja; e) o Direito é laicizado, produto da generalização, dessacralização e racionalização burguesa; e f) desenvolve-se o mercantilismo econômico e o advento da economia monetária.

Por sua vez, a segunda versão do Estado Moderno surgiu como uma reação contra o Estado absoluto. Historicamente, o Estado Liberal nasce da erosão do poder absoluto do rei, tendo como fases mais agudas e culminantes os casos da Inglaterra do século XVII e da França do final do século XVIII (Bobbio, 1990, p. 14). A inspiração desta forma de Estado advém de teorias políticas preocupadas em encontrar um remédio contra o absolutismo do poder do soberano. Desta forma, o problema fundamental do Estado liberal refere-se aos limites do poder estatal. Bobbio (1997, p. 11) leciona que grande parte das teorias elaboradas no curso dos séculos e que levaram à formação do Estado liberal e democrático estão inspiradas em uma ideia fundamental: a de estabelecer limites ao poder do Estado.

Para os fins do presente artigo, importa aprofundar acerca da primeira versão do Estado moderno, isto é, do que se denominou de Estado-Nação, cuja característica mais marcante é a prevalência da soberania como autoridade suprema, representando, assim, a clássica Teoria Geral do Estado. Em outras palavras, o Estado-Nação é aquele que, debruçado sob o pilar da soberania, influi sua jurisdição dentre de um território delimitado e um povo específico (SILVEIRA; FERNANDES, 2016, p. 77).

Os indivíduos eram, portanto, submetidos a um conjunto normativo - Estado de Direito válido dentro daquela comunidade, o que Weber (1991, p. 139) acabou por alcunhar de "dominação legítima", entendida como a "probabilidade de encontrar obediência para ordens específicas (ou todas) dentro de determinado grupo de pessoas".

Vários são os motivos que levam as pessoas a se submeterem a uma dominação, como, por exemplo, o medo ou a afetividade. O que importa destacar é que, segundo Weber (1991, p. 139), a experiência ensina que nenhuma dominação contenta-se somente com estes motivos para a sua persistência. Assim, "todas procuram despertar e cultivar a crença na sua legitimidade". Por isto, a classificação dos tipos puros de dominação weberiana se assenta na natureza da legitimidade que estas dominações pretendem, ou seja, a carismática, a tradicional e a racional-legal.

A dominação carismática se dá “em virtude de devoção afetiva à pessoa do senhor e a seus dotes sobrenaturais (carisma) e, particularmente: a faculdades mágicas, revelações ou heroísmo, poder intelectual ou de oratória" (WEBER, 1991, p. 134). Diz respeito a uma entrega puramente pessoal, que leva em conta as qualidades pessoais da autoridade. Como exemplos cita o mago, o profeta, o príncipe guerreiro, o demagogo (WEBER, 1979, p. 11). Já a dominação tradicional se dá pelo costume, é "baseada na crença cotidiana na santidade das tradições vigentes desde sempre e na legitimidade daqueles que em virtude dessas tradições, representam a autoridade" (WEBER, 1991, p. 141). O tipo mais puro desta dominação - também de caráter pessoal - é a patriarcal, na qual se obedece ao senhor por fidelidade à tradição.

Por último, a sociologia weberiana apresenta uma legitimidade de dominação baseada na legalidade, ou seja, "na crença na validade de preceitos legais e na 'competência' objetiva, fundada sobre normas racionalmente criadas" (WEBER, 1979, p. 11). Trata-se da dominação racional-legal, de caráter impessoal, baseada em estatutos legais, que estabelecem a quem e como se deve obedecer, tal como se viu no Estado-Nação. É fruto, pois, de um processo de racionalização, na 
qual a obediência é devida à lei (Estado de Direito). A este respeito, Bobbio (1997, p. 135) leciona que:

\begin{abstract}
A expressão "Estado de Direito", com a qual os juristas da segunda metade do século passado designaram o Estado Constitucional Moderno, pode ser entendida de diferentes maneiras, mas dois são os significados principais: 1) "Estado de Direito" é o Estado limitado pelo Direito, ou seja, o Estado cujo poder é exercido nas formas do Direito e com as garantias jurídicas pré-estabelecidas; e nesta acepção contrapõe-se ao Estado absoluto; 2) "Estado de Direito" é o Estado que tem como função principal e específica a instituição de um estado jurídico, ou seja, de um Estado no qual, segundo a definição kantiana do Direito, cada um possa coexistir com os outros segundo uma lei universal.
\end{abstract}

Sob uma perspectiva kelseniana, a comunidade social só pode ser constituída por uma ordem normativa. Esta ordem normativa, ao constituir o Estado, transforma-o em uma ordem jurídica, composta por órgãos específicos, que criam e aplicam suas normas, monopolizam o poder de coerção por meio da sanção e apresentam um relativo grau de centralização. Assim, o Estado é uma sociedade politicamente organizada porque é uma comunidade constituída por uma ordem coercitiva e essa ordem coercitiva é o Direito (KELSEN, 1990, p. 91). Nesta ordem de ideias, o Estado detém o monopólio da criação, interpretação e aplicação do Direito tornado obrigatório em virtude do seu poder coercitivo, uma vez que é detentor do monopólio da violência organizada (COELHO, 2003, p. 409).

Constata-se, portanto, como surge e se caracteriza o Estado de Direito Constitucional em cujo Direito estatal não será mais a expressão da vontade do soberano absolutista, mas sim a expressão da vontade da nação soberana, encarnada no Estado. Ele é um produto de diversos fatores econômicos, políticos e sociais, tais como a emergência social da classe burguesa, a consagração do individualismo e da tolerância, a descentralização democrática e separação dos poderes, o princípio da soberania popular e do governo representativo, a supremacia constitucional e o império da lei, a doutrina dos direitos e garantias individuais e a existência de um liberalismo econômico (WOLKMER, 1990, p. 25).

No que se refere à relação entre o Estado e o indivíduo neste contexto de Estado-Nação e, consequentemente, da nacionalidade e o exercício da cidadania, é a ideia de pertença do indivíduo a um grupo que compartilha a mesma cultura, língua e costumes, de modo que lhe seja conferido um estrutura jurídica que forneça segurança, aceitação e referência civilizacional (SILVEIRA; RIPARI, 2009, p. 23).

Neste sentido, a atribuição da nacionalidade - incluindo-se aí as hipóteses de sua perda são prerrogativas estatais como resultado da soberania. Tanto é assim que o artigo 12, inciso I da $\mathrm{CF} / 88$ preconiza que:

São brasileiros:

I - natos:

(a) os nascidos na República Federativa do Brasil, ainda que de pais estrangeiros, desde que não estejam a serviço de seu país;

(b) os nascidos no estrangeiro, de pai brasileiro ou mãe brasileira, desde que qualquer deles esteja a serviço da República Federativa do Brasil; e

(c) os nascidos no estrangeiro de pai brasileiro ou mãe brasileira, desde que sejam registrados em repartição brasileira competente ou venham a residir na República Federativa do Brasil e optem, a qualquer tempo, depois de atingida a maioridade, pela nacionalidade brasileira. 
Em resumo, será atribuída a nacionalidade brasileira ao indivíduo em função do local de nascimento (ius solis) e/ou em função dos laços familiares (ius sanguinis) na modalidade originária. Por outro lado, preza a $\mathrm{CF} / 88$ que terão nacionalidade brasileira derivada aqueles indivíduos submetidos a um processo de naturalização ${ }^{1}$ e observado o artigo 12 , inciso II, in verbis:

São brasileiros:

II - naturalizados:

(a) os que, na forma da lei, adquiram a nacionalidade brasileira, exigidas aos originários de países de língua portuguesa residência por um ano ininterrupto e idoneidade moral; e

(b) os estrangeiros de qualquer nacionalidade, residentes na República Federativa do Brasil há mais de 15 anos ininterruptos e sem condenação penal, desde que requeiram a nacionalidade brasileira.

Para o exercício da cidadania, faz-se necessário, dentro do contexto da Teoria Geral do Estado, a atribuição de uma nacionalidade que, nos dizeres de Mendes (2006, p. 5) "configura vínculo político e pessoal que se estabelece entre o Estado e o indivíduo, fazendo com que este integre uma dada comunidade política, o que faz com que o Estado distinga o nacional do estrangeiro para diversos fins".

É a já ultrapassada ideia de soberania, povo e território como elementos formadores do Estado, tendo a soberania um caráter de absoluto sem levar em consideração que o Estado, após o advento da ONU, deixou de representar um fim em si mesmo, mas um meio de realização de objetivos que abrangem outras esferas, tal como as regionais e internacionais, não somente a doméstica, principalmente com a consolidação do Direito Internacional dos Direitos Humanos. Ademais, a expressão "povo" - restritiva - vai sendo aos poucos substituídas pela expressão "cidadão" como se verá adiante, porquanto a sociedade nos dias atuais encontra-se organizada em estruturas demasiadamente mais complexas que outrora.

\section{A CIDADANIA NA PERSPECTIVA DA TEORIA DA DEMOCRACIA E DO ESTADO CONSTITUCIONAL COOPERATIVO}

Com o término da Segunda Guerra Mundial e o surgimento da ONU e, mais adiante, com o esgotamento da Guerra Fria e, consequentemente com o término da dualidade política mundial, abriu-se um espaço maior na sociedade internacional para diálogos multilaterais sobre os mais variados temas, notadamente acerca da proteção dos Direitos Humanos.

Com o reconhecimento formal e material das organizações internacionais como sujeitos de Direito Internacional Público ${ }^{2}$, os Estados passaram a dividir a responsabilidade com as organizações internacionais de liderar e resolver assuntos de extrema relevância no cenário internacional. Concomitantemente, a Carta de São Francisco, datada de 1945, documento constitutivo da ONU, reconheceu o indivíduo como sujeito de Direito Internacional e como consequência alterou a dinâmica, a relação entre o Estado e o indivíduo.

\footnotetext{
${ }^{1}$ A nova Lei de Migração (Lei n. 13.445, de 24 de maio de 2017) estabelece em seu artigo 64, que a naturalização pode ser: (i) ordinária; (ii) extraordinária; (iii) especial ou (iv) provisória.

${ }^{2}$ Para um maior aprofundamento, ver: FERNANDES, Ana Carolina Souza; SILVEIRA, Vladmir Oliveira da. Sujeitos de Direito Internacional Público: Um Processo Evolutivo de Reconhecimento. Revista Direito \& Paz. Vol. 1. N. 38, 2018.
} 
Neste sentido, os direitos fundamentais se tornaram espécies de uma categoria universal (Direitos Humanos Fundamentais) porquanto se entendia que a proteção de direitos inerentes ao ser humano desconheceria barreiras jurisdicionais (Teoria da Democracia). A incorporação constitucional desta teoria, a partir de meados do século XX, propiciou uma maior penetração do cidadão não somente na coisa pública, mas em todo o processo de formação de vontade do Estado, com vistas a torná-lo, de fato, o destinatário das garantias e direitos fundamentais previstos constitucionalmente (FERNANDES; SILVEIRA, 2016, prelo) ou, até, internalizados por meio de tratados internacionais. E tal fato é visível a partir da leitura dos $\S \S 1^{\circ}$ a $4^{\circ}$ do artigo $5^{\circ}$ da $\mathrm{CF} / 88^{3}$.

Ato contínuo, a soberania, característica marcante dos Estados-Nação, foi, aos poucos, sendo substituída pelo sentimento de solidariedade, cooperação e integração internacionais, reflexo de novos valores que foram surgindo na sociedade, o que levou o teórico Peter Häberle a desenvolver o que acabou por ser alcunhado de Estado Constitucional Cooperativo ${ }^{4}$. Para Häberle, o "Estado Constitucional Cooperativo" é o Estado que justamente encontra a sua identidade também no Direito Internacional, no entrelaçamento das relações internacionais e supranacionais, na percepção da cooperação e responsabilidade internacional, assim como no campo da solidariedade. Ele corresponde, com isso, à necessidade internacional de políticas de paz (2007, p. 04).

A respeito da soberania, Christiane Oliveira Peter da Silva discorre que ${ }^{5}$ :

Isso quer dizer que, ao se falar de povo, não se está a referir a qualquer grupo de indivíduos, mas ao conjunto de cidadãos, reconhecido, protegido, assistido pela Constituição e por outras normas do ordenamento jurídico de um Estado Nacional, chamado país. Quando há uma referência a território, está-se a fazer menção àquele território reconhecido pelas regras de direito internacional, pois se o território não estiver sob a jurisdição das regras de nenhum ordenamento jurídico nacional ou internacional, apresenta-se como um território livre, onde a força e a irracionalidade podem fazer voltar ao tempo das barbáries (vide, por exemplo, a situação de Guantánamo). E a soberania? Esta talvez seja, dentre os elementos do Estado, o que mais trará dificuldades de apreensão e compreensão no século XXI, pois, desde o século XVIII, com a conformação do modelo federal de Estado, tal conceito vem sofrendo sérias transformações, chegando ao século XXI completamente reformulado, em relação ao que dele se concebia em tempos mais remotos.

Neste contexto, entender a nacionalidade e o exercício da cidadania vinculada tão somente a questões territoriais ou sanguíneas, não fazia mais sentido, porquanto a proteção de direito dos indivíduos passou a ser a força motriz das organizações internacionais como um todo. Com efeito,

\footnotetext{
${ }^{3}$ Dispõe referidos parágrafos o que segue:

$\S 1^{\circ}$ As normas definidoras dos direitos e garantias fundamentais têm aplicação imediata.

$\S 2^{\circ}$ Os direitos e garantias expressos nesta Constituição não excluem outros decorrentes do regime e dos princípios por ela adotados, ou dos tratados internacionais em que a República Federativa do Brasil seja parte.

$\S 3^{\circ}$ Os tratados e convenções internacionais sobre direitos humanos que forem aprovados, em cada Casa do Congresso Nacional, em dois turnos, por três quintos dos votos dos respectivos membros, serão equivalentes às emendas constitucionais.

$\S 4^{\circ} \mathrm{O}$ Brasil se submete à jurisdição de Tribunal Penal Internacional a cuja criação tenha manifestado adesão.

${ }^{4}$ Para um maior aprofundamento, ver: HÄBERLE, Peter. Estado Constitucional Cooperativo. Tradução do original em alemão por Marcos Augusto Maliska e Elisete Antoniuk. Porto Alegre: Livraria do Advogado, 2007.

${ }^{5}$ SILVA, Christine Oliveira Peter da. Estado Constitucional Cooperativo: O Futuro do Estado e da Interpretação Constitucional sob a Ótica da Doutrina de Peter Häberle. Disponível em: <https://www.planalto.gov.br/ccivil_03/revista/revistajuridica/index.htm>. Acesso em: 09 de março de 2018.
} 
o processo de integração da União Europeia desafiou a soberania enquanto poder máximo do Estado, isto é, as próprias ideias de Estado conforme formulado por Jean Bodin. É preciso, pois, entender que as transformações das relações entre Estado e indivíduo estarão intrinsecamente ligadas à realidade e o contexto social de um determinado momento histórico.

Após os horrores e violências acometidas na Segunda Guerra Mundial aos seres humanos, passou-se a entender que o Estado só se justifica se estiver a serviço da dignidade da pessoa humana (MALISKA, online, p. 7023). É possível discorrer, ainda neste sentido, que a ampliação do conceito de cidadania decorre da dinamogenesis dos direitos humanos e da compatibilização de valores que colocam a dignidade da pessoa humana num novo patamar, mais complexo (CAMPELO; SILVEIRA, 2011, p. 87). Segundo Fernandes e Silveira (2016, p. 77), o processo de dinamogenesis dos direitos humanos 6 :

teve início a partir da famosa tríade da Revolução Francesa (Liberdade, Igualdade e Fraternidade), em especial, com a Declaração dos Direitos do Homem e do Cidadão (1789) e se concretizou com a Declaração Universal dos Direitos Humanos (1948), ensejando a promulgação de diversos tratados internacionais com o fito de proteger direitos básicos do indivíduo, na qual, dentre os mais significativos, podemos citar o Pacto Internacional dos Direitos Econômicos, Sociais e Culturais e o Pacto Internacional dos Direitos Civis e Políticos, ambos de 1966.

Assim, tanto o conceito de nacionalidade quanto o conceito de cidadania passam por um processo de construção histórica que teve início na Revolução Francesa, sofrendo diversas alterações com o decurso do tempo. Portanto, não são conceitos estáticos, mas fruto do progresso da humanidade e a partir de novas perspectivas históricas, cuja consequência imediata é o redimensionamento do vínculo jurídico-político, tal como foi visto na transição do Estado medieval (constituído por feudos) para o Estado absolutista (fundado por uma monarquia absolutista) e, agora, para o Estado Constitucional Cooperativo. Inclusive, é possível identificar na CF/88 essa transição a partir da leitura do artigo $4^{\circ}$ e seu parágrafo único, in verbis:

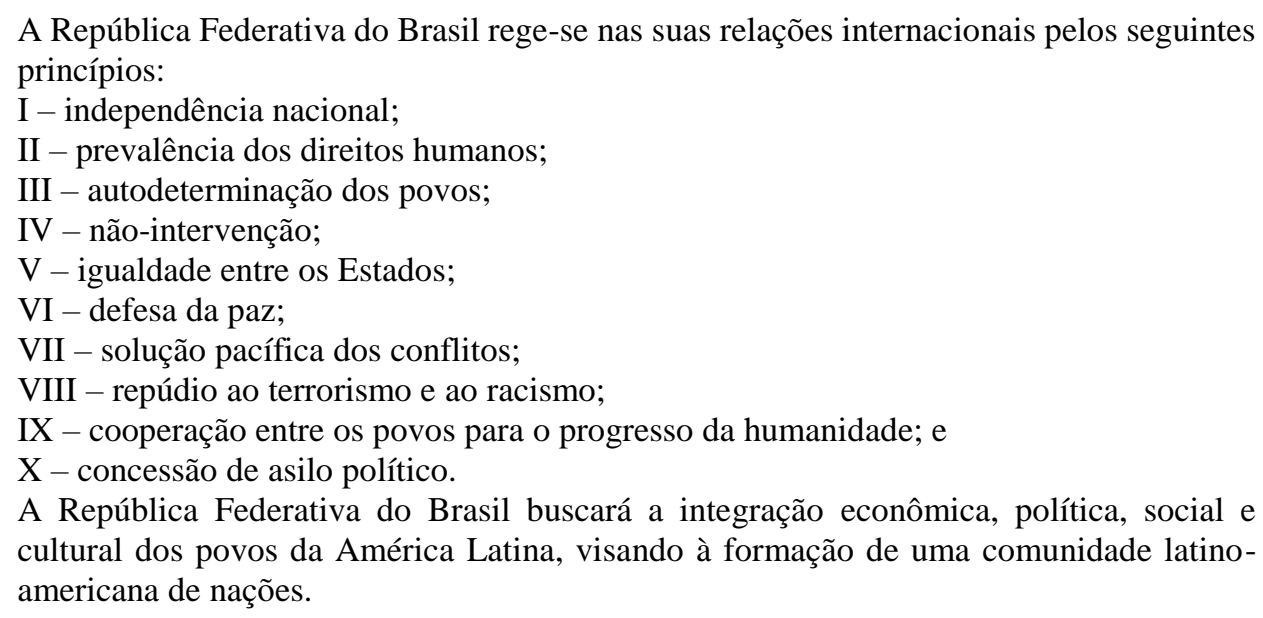

Verifica-se, pois, que a ordem internacional atual tem grande influência nos Estados Constitucionais e os Estados que outrora se repousavam na soberania para justificar seus atos perante à sociedade internacional passaram a ter uma visão solidária e cooperativa, ainda que em

\footnotetext{
${ }^{6}$ Para um maior aprofundamento, ver: SILVEIRA, Vladmir Oliveira da; ROCASOLANO, Maria Mendez. Direitos Humanos: Conceitos, Significados e Funções. São Paulo: Editora Saraiva, 2010, p. 184-202.
} 
alguns poucos casos haja um contra fluxo de natureza nacionalista como se viu nas últimas eleições norte-americanas (Trump), brasileiras (Bolsonaro) e até mesmo o processo de saída do Reino Unido da União Europeia (conhecido como Brexit). Assim, o modelo que se estabeleceu com a Paz de Vestefália não mais se coaduna com a dinâmica do mundo atual, globalizado, multicultural, veloz e fluído. Neste sentido, é importante rememorar as lições de J. J. Canotilho (2002, p. 90)7

O Estado, tal com acaba de ser caracterizado, corresponde, no essencial, ao modelo de Estado emergente da Paz de Westfália (1648). Este modelo, assente, basicamente, na ideia de unidade política soberana do Estado, está hoje relativamente em crise como resultado dos fenômenos da globalização, da internacionalização e da integração interestatal.

A relação entre o Estado e indivíduo não se traduz mais no binômio súdito-soberano; mas de forma uma mais abrangente, difusa e universal pautados nos corolários da Revolução Francesa - ou dimensões dos Direitos Humanos - e tendo como fundamentos os direitos naturais fundamentais. Assim, satisfeitas as dimensões dos Direitos Humanos, isto é, tendo sido desenvolvido o processo de dinamogenesis de forma satisfatória e os direitos afirmados - é que se fala em cidadania plena, independentemente do local de origem do indivíduo, porquanto parte-se da premissa de que todos são iguais perante a lei, seja ela doméstica, seja ela regional, seja ela internacional.

A cultura e a filosofia neste início da modernidade são marcadas pela reafirmação do sujeito e da razão individuais, a partir de um novo postulado antropológico, que vê no homem um "ser natural, um elemento de um mundo concebível segundo leis naturais" (FERRAZ, 1980, p. 24). Não por outra razão que Bob Jessop (1995, p. 9) assim disserta a respeito do Estado-Nação no contexto europeu que estava na fase inicial de seu processo de integração:

\footnotetext{
Em primeiro lugar, a desnacionalização do Estado, um certo esvaziamento do aparelho do Estado nacional que decorre do fato de as velhas e novas capacidades do Estado estarem a ser organizadas, tanto territorial quanto funcionalmente, aos níveis subnacional e supranacional. Em segundo lugar, a desestatização dos regimes políticos refletida na transição do conceito de governo (government) para a governação (governance), ou seja, de um modelo de regulação social e econômica assente no papel central do Estado para um outro assente em parcerias e outras formas de associação entre organizações governamentais, para-governamentais e não-governamentais, nas quais o aparelho do Estado tem apenas tarefas de coordenação enquanto primus inter partes. E, finalmente, uma tendência para internacionalização do Estado nacional expressa no aumento do impacto estratégico do contexto internacional na atuação do Estado, o que pode envolver a expansão do campo de ação do Estado nacional sempre que for necessário adequar às condições internas às exigências extraterritoriais ou transnacionais.
}

Nesse sentido, a questão da cidadania extrapola o tradicional vínculo entre o Estado e o indivíduo em razão da nova realidade mundial em se que preza um modelo de Estado cooperativo, integrativo e solidário, voltado à proteção dos direitos dos cidadãos como um todo e não unicamente do seu próprio "povo" devido às características transnacionais das sociedades contemporâneas.

Sob o ponto de vista do ordenamento jurídico brasileiro, a despeito dos artigos constitucionais já mencionados, pode-se citar a nova Lei de Migração (Lei n. 13.445, de 24 de maio de 2017) que substituiu o malfado Estatuto do Estrangeiro (Lei n. 6.815, de 19 de agosto de 1980).

${ }^{7}$ CANOTILHO, J. J. Gomes. Direito constitucional. 5.ed. Livraria Almedina: Coimbra, 2002, p. 90. 
Ao passo que o Estatuto via o migrante como uma ameaça à segurança nacional, naquela, isto é, na nova Lei o migrante passou a ser considerado portador de direitos e obrigações, portanto, sujeito de direito e digno de proteção, ainda que não detentor da nacionalidade brasileira, porquanto ser humano.

\section{A TRANSNACIONALIDADE DA CIDADANIA E O INSTITUTO DA EXTRADIÇÃO}

Como dito outrora, a cidadania estava entrelaçada à vinculação de um indivíduo a determinado Estado, implicando em um sentimento de pertencimento, isto é, "o estabelecimento de uma personalidade em um território geográfico" (VIEIRA, 2001, p. 34). Todavia, o mundo atual é globalizado, multicultural e transnacional e, levando em consideração essas características, a cidadania também deve ser encarada de uma perspectiva mais ampla, que vai além de direitos civis (liberdades) e políticos (votar e ser votado).

O exercício da cidadania é um processo. E, nesse processo, ao cidadão implica uma continuidade no exercício de deveres perante os demais e perante o Estado. E vai além: exige-se, ainda, a plenitude da realização destes direitos (PELLENZ; BASTIANI; SANTOS, 2015, p. 7). E a plenitude desses direitos está vinculada à consolidação do Direito Internacional dos Direitos Humanos, como também com a consciência da necessidade de envolvimento dos indivíduos na defesa destes. Por isso que Pérez Luño leciona que "las nuevas condiciones de ejercicio de los derechos humanos han determinados uma nueva forma de ser ciudadano en el Estado de Derecho de las sociedades tecnológicas, del mismo modo que el trânsito desde el Estado liberal al Estado social de Derecho configuro también formas diferentes de ejercitar la ciudadanía"8 (2006, p. 35).

Considerando o contexto global e transnacional e considerando que o Estado, na maioria das vezes, é o maior violador dos Direitos Humanos, restam aos próprios indivíduos buscar os meios para garantir a existência não somente formal de seus direitos, mas que eles também possam ser objeto de efetiva concretização, ainda que fora do âmbito doméstico. Neste sentido, os fenômenos da globalização, da transnacionalização e do globalismo contribuíram em certa medida para a formação de um indivíduo ciente de seu papel na sociedade.

A globalização nada mais é do que a abertura de barreiras, não somente econômicas, mas também territorial, permitindo, assim, a livre circulação de pessoas, informações, bens e serviços, etc. Inferir que a globalização é um processo de natureza exclusivamente econômica, impulsionado por forças de mercado e mudanças tecnológicas autônomas é um dos equívocos mais recorrentes. Trata-se, leciona Diniz (2007, p. 24-25), de uma simplificação, pois o processo de globalização é essencialmente um fenômeno multidimensional. Consenso, no entanto, é que a globalização se apresenta como um fenômeno de caráter irreversível.

Por outro lado, leciona Stelzer (2011, p. 21) que:

a transnacionalização pode ser compreendida como um fenômeno reflexivo da globalização, que se evidencia pela desterritorialização dos relacionamentos políticossociais, fomentado por sistema econômico capitalista ultravalorizado, que articula ordenamento jurídico mundial à margem da soberania dos Estados. A transnacionalidade insere-se no contexto da globalização e liga-se fortemente com a concepção do transpasse estatal. Enquanto a globalização remete à ideia de conjunto, de globo, enfim, o mundo

\footnotetext{
8 Tradução livre das autoras: "as novas condições do exercício dos direitos humanos determinaram uma nova forma de ser cidadão no Estado de Direito das sociedades tecnológicas, do mesmo modo que a transição do Estado liberal ao Estado social de Direito também configurou formas diferentes de exercitar a cidadania”.
} 
sintetizado como único; transnacionalização está atada à referência de Estado permeável, mas tem na figura estatal a referência do ente em declínio.

E para finalizar a tríade acima mencionada, tem-se o globalismo. Referido fenômeno nada mais é do que uma política internacionalista, implementada por burocratas, com vistas a "lidar com os problemas cada vez mais complexos deste mundo - que vão desde crises econômicas até a proteção do meio ambiente", que "requer um processo centralizado de tomada de decisões, em nível mundial", isto é, supranacional. Em outras palavras, a ideia de Estado-Nação passou a ser obsoleta e a soberania passou a ser compartilhada com outros sujeitos de Direito Internacional Público (POLLEIT, 2017, online).

Todos esses fatores em conjunto contribuíram sobremaneira para estabelecer essa nova concepção de cidadania, ou seja, a cidadania transnacional, intrinsecamente relacionada à proteção e defesa dos "cidadãos do mundo", sem se limitar à noção de "identificação nacional" Isso porque, não obstante não ser um problema recente, o fluxo migratório está cada vez mais assente. Veja, por exemplo, a migração de venezuelanos para o Brasil e para a Colômbia ou, até mesmo, no âmbito da União Europeia com a chegada em massa de sírios ou outros asiáticos e indivíduos de origem muçulmana, trazendo à tona preocupações e desafios diversos. Isso sem contar com relacionamento entre pessoas de diferentes nacionalidades.

Em uma sociedade plural e multicultural como a atual, "cada homem e cada mulher deve ser alvo de um tríplice reconhecimento, ou seja, devem encontrar igual proteção e igual respeito em sua integridade: enquanto indivíduos insubstituíveis, enquanto membros de um grupo étnico ou cultural e enquanto cidadãos, ou membros de uma comunidade política" (HABERMAS, 1997, p. 284-285). Neste sentido, a própria abrangência de cidadania se amplia, nos seguintes termos:

Se por muito tempo o uso linguístico do termo cidadania fazia referência a um vínculo único e exclusivo entre o indivíduo e o Estado, nas circunstâncias atuais é possível admitir uma pluralidade de cidadania. Em outros termos, substituir a cidadania unilateral por uma cidadania multilateral (CADEMARTORI, 2011, p. 143).

Dentro de todo esse contexto, resta-nos explorar a problemática deste artigo, isto é, o instituto da extradição em face da cidadania transnacional, utilizando-se como pano de fundo a recente decisão do STF no Mandado de Segurança n. 33.864.

Em linhas gerais, a referida ação objetivou revogar portaria do Ministério da Justiça acerca da perda de nacionalidade nata de Cláudia Cristina Sobral, cidadã brasileira que residiu nos Estados Unidos. Em determinado momento contraiu matrimônio, o que lhe garantiu o green card. Divorciou-se. Porém, para exercer seu ofício de contadora naturalizou-se norte-americana, fazendo juramente a bandeira. Casou-se novamente. Porém, em 2007, seu segundo marido foi encontrado morto em casa e esta retornou ao Brasil. Diante deste fato, as autoridades norte-americanas a denunciaram por homicídio qualificado. Cláudia estava no Brasil e o governo norte-americano requereu pedido de prisão preventiva na Extradição n. 694, alegando, dentre outros, que Cláudia fugiu para o Brasil para não ter de responder por seus atos, protegida por sua nacionalidade brasileira, muito embora detentora, naquele momento, da nacionalidade (derivada) norteamericana.

No âmbito do Mandado de Segurança n. 33.864, o entendimento majoritário da Primeira Turma do STF foi de que ao jurar à bandeira e prometer fidelidade aos Estados Unidos da América, houve, por parte da Cláudia, uma declaração unilateral de vontade de renúncia de sua nacionalidade. Como consequência, deixaria de ser brasileira e, portanto, de se ver protegida pelas 
leis brasileiras e pela legislação internacional a qual o Brasil está vinculado, notadamente no que diz respeito à proteção dos Direitos Humanos.

Não nos cumpre aqui adentrar pormenorizadamente no assunto, mas o que salta aos olhos foi a forma arbitrária na qual a sua nacionalidade originária - e consequentemente o exercício de sua cidadania - lhe foi retirada, sem a observância da própria legislação doméstica ou até mesmo de importantes instrumentos internacionais que tratam da temática. Com efeito, se pensarmos nas dezenas de milhares de cidadãos brasileiros que se encontram na mesma situação da Cláudia, que poderão perder seus direitos fundamentais e poderão enfrentar o risco de uma possível situação de apatria, verificar-se-á a perversidade da decisão do STF.

Note-se que o artigo 15 da Declaração Universal dos Direitos Humanos (1948) preconiza que "toda pessoa tem direito a uma nacionalidade, a qual ninguém será arbitrariamente privado dela, nem do direito de mudar de nacionalidade". Nesta mesma esteira, o artigo 20 da Convenção Americana sobre Direitos Humanos (1969) dispõe que "1. Toda pessoa tem direito a uma nacionalidade; 2 . Toda pessoa tem direito à nacionalidade do Estado cujo território houver nascido, se não tiver direito a outra; e 3. A ninguém se deve privar arbitrariamente de sua nacionalidade nem do direito de mudá-la".

A razão de ser dessas disposições é cristalina: afastar a apatria ${ }^{9}$, porquanto é inerente ao ser humano pertencer a alguma comunidade. Nos dizeres de Hannah Arendt (2012), "ser privado de nacionalidade é como ser privado da pertença ao mundo, é como retornar ao estado natural, como homens das cavernas ou selvagens (...). O homem que não é nada mais que um homem perdeu aquelas qualidades que tornaram possível para outras pessoas o tratarem como igual”.

Assim, a legislação internacional busca proteger a manutenção da cidadania de um indivíduo ou, ainda, a perda arbitrária dela, que foi justamente o ocorreu no Mandado de Segurança n. 33.864. Sob esse enfoque, Cláudia corre um duplo risco. O primeiro refere-se ao fato de que, em tendo sido a sua naturalização norte-americana aprovada e concedida (nacionalidade derivada), sua cidadania pode ser revogada a qualquer momento, sem que seu processo criminal tenha efetivamente transitado em julgado. O segundo é consequência do primeiro. A possibilidade da apatria, o que tanto a legislação internacional quando a legislação doméstica em seu artigo $5^{\circ}$, inciso XLVVII, item "d" (que proíbe a pena de banimento, utilizada, muitas vezes, em regimes de exceção e não democráticos) busca evitar.

Importa esclarecer, igualmente, que a extradição, sob o prisma do ordenamento jurídico pátrio, só é permitido em casos em que já exista uma condenação privativa de liberdade ou que a prisão tenha sido decretada por juiz competente, o que não foi o caso de Cláudia na época em que a sua extradição foi autorizada em 2017. Ademais, por determinação constitucional, seria vedada a extradição de brasileiro nata (artigo $5^{\circ}$, inciso LII), o que não se observou no caso em tela. A jurisprudência dominante até então seguia a mesma linha de raciocínio. Vejamos, pois, a decisão do Habeas Corpus n. 83.113-3/DF:

O brasileiro nato, quaisquer que sejam as circunstâncias e a natureza do delito, não pode ser extraditado, pelo Brasil, a pedido de Governo estrangeiro, pois a Constituição da República, em cláusula que não comporta exceção, impede, em caráter absoluto, a efetivação da entrega extradicional daquele que é titular, seja pelo critério do "jus solis", seja pelo critério do "jus sanguinis", de nacionalidade brasileira primária ou originária. (...). Esse privilégio constitucional que beneficia, sem exceção, o brasileiro nato $(\mathrm{CF}$, art.

\footnotetext{
${ }^{9}$ A Convenção das Nações Unidas sobre o Estatuto dos Apátridas, vigente no ordenamento jurídico brasileiro por meio da edição do Decreto n. 4.246, de 22 de maio de 2002, dispõe que “o termo 'apátrida' designará toda pessoa que não seja considerada seu nacional por nenhum Estado, conforme sua legislação” (artigo 1, item 1).
} 


\begin{abstract}
$5^{\circ}$, LI), não se caracteriza pelo fato de o Estado estrangeiro, por lei própria, haver-lhe reconhecido a condição de titular de nacionalidade originária pertinente a esse mesmo Estado (CF, art. 12, § $4^{\circ}$, II, "a"). (...). Se a extradição não puder ser concedida, por inadmissível, em face de a pessoa reclamada ostentar a condição de brasileira nata, legitimar-se-á a possibilidade de o Estado brasileiro, mediante a aplicação extraterritorial de sua própria Lei Penal (CP, art. $7^{\circ}$, II, "b", e respectivo $\left.\S 2^{\circ}\right)$ e fazer instaurar, perante o órgão judiciário nacional competente (CPP, art. 88), a concernente "persecutio criminis", em ordem a impedir, por razões de caráter ético-jurídicos que práticas delituosas, supostamente cometidas, no exterior, por brasileiros natos ou naturalizados, fiquem impunes.
\end{abstract}

Refrise-se que a relação entre o Estado e o indivíduo foi alterada e muito embora o Estado tenha soberania para regular certos aspectos da vida em sociedade, a questão da nacionalidade e consequentemente o exercício da cidadania encontra-se sob proteção dos Direitos Humanos. Suprimir direitos inerentes ao ser humano - direito à nacionalidade - e, pior, submeter o indivíduo a uma condição que a legislação internacional repudia - in casu, a apatria - é o caso clássico do Estado como sendo violador dos Direitos Humanos.

\title{
CONCLUSÃO
}

O presente artigo buscou analisar a evolução do conceito de cidadania, sob o ponto de vista das diferentes perspectivas na relação entre o Estado e o indivíduo. Em um primeiro momento, investigou-se a questão da nacionalidade e o exercício da cidadania, a partir de um formato do Estado arquitetado por Jean Bodin, pautado na soberania. Na sequência, examinou-se a cidadania em um contexto pós-Segunda Guerra que alterou sobremaneira o cenário internacional impulsionando um ramo do Direito Internacional outrora inexistente, a saber: o Direito Internacional dos Direitos Humanos. E, por fim, com base neste cenário atualmente consolidado, averiguar como o atual entendimento da cidadania, com características transnacionais, limitaria certos poderes do Estado, em especial, em casos de extradição que viesse a ferir disposições não somente do Direito doméstico, mas, principalmente, do Direito Internacional.

A concepção inicial de Estado surgiu com o fim do modelo feudal da polis chamado de absolutista porquanto legitimado pelo poder do Rei, a quem se devia obediência. O Estado absolutista procurou organizar os diversos ordenamentos jurídicos em um único sistema, para melhor controle e supervisão dos indivíduos sob sua jurisdição. O Rei detinha um poder supremo e, neste modelo, o Estado era nacional (Estado-Nação). Assim, tem-se o contexto da teoria clássica do Estado, formado pela soberania, por um território delimitado e por um povo específico, submetidos a um conjunto normativo válido tão somente dentro daquela comunidade.

No Estado-Nação, a relação entre o Estado e o indivíduo fundava-se no sentimento de pertencimento, porquanto conferia segurança e até mesmo referência civilizacional. Neste contexto, o direito à nacionalidade era uma prerrogativa do Estado, sem a qual o indivíduo não tinha qualquer controle.

Não obstante, após os horrores acometidos na Segunda Guerra Mundial, na qual atrocidades foram cometidas contra seres humanos, a ONU assumiu a dianteira de assuntos relevantes para a sociedade internacional, dentre eles, os Direitos Humanos. Neste contexto, houve três alterações bastante significativas. A primeira foi que a expressão "povo" foi substituída por "cidadão". A segunda foi uma maior abertura às relações multilaterais. E a terceiro foi que a noção de soberania, até então um conceito intocável, passou a ser relativizada para compatibilizar a tutela complementar das organizações internacionais. Essas mudanças foram possíveis graças ao 
reconhecimento das organizações internacionais, notadamente a ONU, como sujeitos de Direito Internacional Público. Como consequência, alterou-se novamente a relação entre o Estado e o indivíduo, porquanto se reconheceu os direitos fundamentais como uma espécie do gênero "direitos humanos fundamentais" transpondo barreiras jurisdicionais.

A clássica Teoria Geral do Estado deu espaço à Teoria da Democracia, tudo com vistas a: (i) tornar o cidadão partícipe do processo de formação de vontade do Estado e (ii) ser o efetivo destinatário de direitos e garantias. Os sentimentos de solidariedade, cooperação e integração passaram a compor a dimensão pessoal do Estado e não mais apenas a soberania absoluta - mas a soberania compartilhada nos moldes proposto pelo Estado Constitucional Cooperativo, na qual o exercício da cidadania está intrinsecamente ligado à garantia da dignidade.

A cooperação entre os Estados, aliado ao surgimento do fenômeno da globalização, impulsionou ainda mais o alargamento do conceito de cidadania, tornando-a transnacional. Assim, a transnacionalidade da cidadania é evidenciada pela desterritorialização das relações políticas e sociais estatais, afastando-se da noção de identidade nacional, tendo em vista a pluralidade e multiculturalidade da sociedade. Neste sentido, passou-se a admitir no cenário internacional uma pluralidade de cidadania.

Diante deste contexto, buscou-se analisar a extradição de Cláudia Cristina Sobral, objeto do Mandado de Segurança n. 33.864, em face da cidadania transnacional. Cláudia, cidadã brasileira que, por ato administrativo, perdeu de forma arbitrária e unilateral sua nacionalidade brasileira originária, com o risco de se tornar apátrida, violando importantes disposições normativas não somente domésticas, mas também internacionais. No que diz respeito à legislação brasileira, a $\mathrm{CF} / 88$ é clara ao vedar a pena de banimento. Por sua vez, os principais instrumentos internacionais não admitem a privação arbitrária da nacionalidade. Inclusive, reiteram o direito do indivíduo a uma nacionalidade.

Independentemente do pano de fundo que justificou a extradição de Cláudia, o Estado brasileiro, por meio do STF, órgão de proteção máxima dos direitos fundamentais, equivocou-se ao negar vigência aos princípios e as regras mais elementares dos Direitos Humanos, como também direitos da Cláudia enquanto ser humano. Com efeito, Cláudia foi privada, dentre outras coisas, de sua nacionalidade brasileira e corre ainda o risco de eventual apatria, caso as autoridades norteamericanas decidam revogar sua naturalização. Situações como essas exemplificam a razão pela qual as organizações internacionais passaram a ter um papel de extrema relevância no cenário internacional e as relações entre Estados e indivíduos precisaram ser revistas.

\section{REFERÊNCIAS}

ARENDT, Hannah. Origens do Totalitarismo: Antissemitismo, Imperialismo e Totalitarismo. 4.reimp. Tradução de Roberto Raposo. São Paulo: Companhia das Letras, 2012, apud ALTO COMISSARIADO DAS NAÇÕES UNIDAS PARA REFUGIADOS. Nacionalidade e Apatridia: Manual para Parlamentares. Disponível em: <http://www.ipu.org/PDF/publications/nationality_p.pdf>. Acesso em 10 de março de 2019.

BOBBIO, Norberto. Direito e Estado no Pensamento de Emanuel Kant. 4 ed. Brasília: UnB, 1997.

CADERMATORI, Daniela Mesquita Leutchuk. Limites e Possibilidades de uma Cidadania Transnacional: Uma Apreensão Histórico-Conceitual. In: CRUZ, Márcio Paulo; STELZER, Joana (orgs.). Direito e Transnacionalidade. Curitiba: Juruá, 2011. 
CAMPELLO, Lívia Gaigher Bósio; SILVEIRA, Vladmir Oliveira da. Cidadania e Direitos Humanos. In: PEREIRA, Antonio Celso Alves; MELLO, Cleyson de Moraes (coords.). Revista Interdisciplinar de Direito da Faculdade de Direito de Valença/Fundação Educacional D. André Arcoverde. Juiz de Fora: Editora Associada, 2011.

CANOTILHO, J. J. Gomes. Direito constitucional. 5.ed. Livraria Almedina: Coimbra, 2002.

DALLARI, Dalmo de Abreu. Elementos de Teoria Geral do Estado. São Paulo: Editora Saraiva, 2003.

DINIZ, Eli (org.). Globalização, Estado e Desenvolvimento: Dilemas do Brasil no Novo Milênio. Rio de Janeiro: FGV, 2007.

FERNANDES, Ana Carolina Souza; SILVEIRA, Vladmir Oliveira da. Complementariedade de Jurisdição e Proteção aos Direitos Humanos sob a Perspectiva da Teoria Tridimensional da Cidadania: O Caso Pfizer vs. Abdullahi. In: BENACCHIO, Marcelo (coord.). A Sustentabilidade da Relação entre Empresas Transnacionais e Direitos Humanos. Curitiba: CRV, 2016a, p. 73-93.

FERNANDES, Ana Carolina Souza; SILVEIRA, Vladmir Oliveira da. Sujeitos de Direito Internacional Público: Um Processo Evolutivo de Reconhecimento. Revista Direito \& Paz. Vol. 1. N. 38, 2018.

FERNANDES, Ana Carolina Souza; SILVEIRA, Vladmir Oliveira da. A Crise de Refugiados na União Europeia e a Proteção dos Direitos Humanos sob a Perspectiva do Estado Constitucional Cooperativo. In: IENSUE, Geziela; CARVALHO, Luciani Coimbra de (org.). Migração, Direitos Humanos e Cooperação Jurídica Internacional. 1.ed., vol. 1, $2016 \mathrm{~b}$.

FERRAZ JÚNIOR, Tércio Sampaio. A Ciência do Direito. 2.ed. São Paulo: Atlas, 1980.

HÄBERLE, Peter. Estado Constitucional Cooperativo. Tradução do original em alemão por Marcos Augusto Maliska e Elisete Antoniuk. Porto Alegre: Livraria do Advogado, 2007.

HABERMAS, J. Cidadania e Identidade Nacional. In: Direito e Democracia: Entre Facticidade e Validade. Tradução de Flávio B. Siebeneichler. Rio de Janeiro: Tempo Brasileiro, 1997.

KELSEN, Hans. Teoria Geral do Direito e do Estado. Tradução por Luís Carlos Borges. São Paulo: Martins Fontes; Brasília: Editora UnB, 1990.

MALISKA, Marcos Augusto. A Cooperação Internacional para os Direitos Humanos entre o Direito Constitucional e o Direito Internacional: Desafios ao Estado Constitucional Cooperativo. Acesso em:

<www.publicadireito.com.br/conpedi/.../bh/marcos_augusto_maliska.pdf>. Acesso em 06 de março de 2018.

MENDES, Gilmar Ferreira. Direito de Nacionalidade e Regime Jurídico do Estrangeiro. Direito Público: Porto Alegre, v. 4, n. 14, out./dez. 2006. 
PELLENZ, Mayara; BASTIANI, Ana Cristina Bacega de. A (Re)Significação da Cidadania na Contemporaneidade. Athenas. Vol. 1, Ano IV, Jan./Out. 2016. p. 02-29.

POILLET, Thorsten. A Diferença Básica entre Globalismo e Globalização Econômica: Um é o Oposto do Outro. Disponível em: <https://www.mises.org.br/Article.aspx?id=2639>. Acesso em 10 de março de 2018.

SILVA, Christine Oliveira Peter da. Estado Constitucional Cooperativo: O Futuro do Estado e da Interpretação Constitucional sob a Ótica da Doutrina de Peter Häberle. Disponível em: $<$ https://www.planalto.gov.br/ccivil_03/revista/revistajuridica/index.htm>. Acesso em: 09 de março de 2018.

SILVEIRA, Vladmir Oliveira da; RIPARI, Vanessa Toqueiro. A Cidadania Regional Americana e o Ordenamento Jurídico. Revista da Escola Paulista de Magistratura. Vol. 5, 2009, pp. 22-28.

SILVEIRA, Vladmir Oliveira da; ROCASOLANO, Maria Mendez. Direitos Humanos: Conceitos, Significados e Funções. São Paulo: Editora Saraiva, 2010.

SKINNER, Quentin. As Fundações do Pensamento Político Moderno. Tradução por Renato Janine Ribeiro e Laura Teixeira Motta. São Paulo: Companhia das Letras, 1996.

STELZER, Joana. O Fenômeno da Transnacionalização da Dimensão Jurídica. CRUZ, Paulo Márcio; STELZER, Joana (orgs.). Direito e Transnacionalidade. 1.ed. Curitiba: Juruá, 2011.

VIEIRA, Liszt. Os Argonautas da Cidadania: A Sociedade Civil na Globalização. Rio de Janeiro: Record, 2001.

WEBER, Max. Os Três Tipos Puros de Dominação Legítima. In: COHN, Gabriel (org). WeberSociologia. 5.ed. São Paulo: Ática, 1991.

WOLKMER, Antonio Carlos. Elementos para uma Crítica do Estado. Porto Alegre: Sergio Fabris Editor, 1990. 